\title{
O TEMPO NA TEMÁTICA DO CONTO MACHADIANO
}

CASSIANA LACERDA

A consciência do tempo em suas minimas parcelas constitutivas por imposição da sociedade industrializada, fêz do homem moderno um escravo do relógio.

Paradoxalmente, nunca a literatura se preocupou tanto com - problema do tempo como medida irregular, pessoal, enfim com a relatividade subjetiva da "durée", constituindo-se quase que numa coracterística da prosa do século $X X$.

No caso de Machado de Assis, é lugar comum apontá-lo como precursor da ficção moderna, principalmente pela atenção que conferiu à problemática do tempo como dimensão romanesca.

O tempo é um dos temas constantes na obra de Machado à qual conferiu transcendência não sòmente do ponto de vista das reflexões que o transforma em tema explícito, pela maneira com que sentiu a experiência humana, mas, sobretudo, pelas soluções antecipadas de técnica e composição.

O tema, como tal, não apresenta qualquer interêsse de novidade, é uma constante na literatura de todos os tempos.

A inovação em Machado está na maneira de sentí-lo dentro da experiência humana e configurá-lo na estrutura da ficção.

$E^{\prime}$ sem dúvida alguma "a experiência do tempo", o pensamento central que contribui para o "clima de insegurança", para - "gôsto de cinza" na busca de sentido e compreensão do ilogismo humano.

Os críticos já observaram que as linhas mestras da obra machadiana estão definidas em seus contos, como num "Iaboratório fecundo" ou como em "estudos" que prepararam ou mesmo suplantaram as grandes "telas".

No entanto, a mesma bibliografia critica nos mostra que a preocupação maior dos estudiosos recai nos romances.

Wilton Cardoso no apêndice de seu estudo Tempo e Memória de Machado de Assis, ${ }^{1}$ já ressalta a dificuldade em examinar o tema do tempo nos contos machadianos, pois, êle se nos 
apresenta como uma "visão de caleidoscópio", onde "o tempo assume formas e coloraçōes que se fundem e se confundem numa orgia de impressōes disformes."

No entanto, acreditamos que o maior obstáculo não está apenas no aspecto heterogêneo dos contos, mas sobretudo no seu método de composição - Machado não explica a conceituaçãa do tempo ou qualquer conceituação, pois fêz do "capricho sua regra de composição". E' inimigo dos conceitos, ainda que comentando qualquer ato humano através de seu aspecto subjetivo de coisa antes pensada que vivida, o que existe é uma atmosfera filosófica e, sobretudo, uma interpretação estética.

Os contos "Lógrimas e Xerxes" " e "Viver" 3 podem ser considerados o resumo de sua "filosofia", onde coloca o problema do tempo dentro de total relativismo, criando um climax de mitização, submetendo a idéia do tempo a vários símbolos.

Em "Lógrimas de Xerxes" o tempo é desintegrado, subvertido pela posição em que se coloca o autor confundido com a sabedoria e a eternidade dos ventos "que andam cá e lá, abaixo e acima, de um tempo a outro tempo, e sabem muito porque são testemunhas de tudo".

$E$, é pelos ventos que Frei Lourenço descobre ser o maior despota, um escravo do tempo. Porisso, Xerxes chorou ao pensar que daqueles homens, por êle comandados, nenhum existiria ao cabo de um século.

As lágrimas "que a brevidade da vida arrancou" transformadas em astros, não brilharam como uma estrêla de melancolia", mas como "ostro de ironia" luzindo sôbre os homens que passam.

"Onde as bodas cantarem a eternidade, ela fará descer um dos seus raios, lágrimas de Xerxes, para escrever a palavra extinsão, breve, total, irremissivel".

O universo imortal humilha o homem mortal, que tem, como resposta à sua ânsia de eternidade, o fluir irreversível do tempo.

A "estrêla de ironia" brilha como o enfado e a tristeza do humour machadiano, como forma de protesto diante da certeza terrivel de que os males que nos atingem são irreparáveis.

Dilacerado pela mesma certeza Ahasverus assistiu ao espetáculo do tempo - o eterno repetir de aleluias e acasos.

Sua posição de "último dos homens", o lucidez de quem leu todo o livro absurdo da vida, é semelhante à do humorista na altivez dolorosa daquele que compreendeu ser a vida e o cosmos uma farça, podendo, portanto, zombar de tudo.

"Felizes os que só leram a vida em um capítulo. Os que se foram à nascença dos impérios levaram a impressão de perpetuidade dêles", diz a mesma personagem do conto "Viver".

Porém, como acentuou Alcides Maya", se humour é revolta, é também melancolia e piedade. Revolta e compaixão de 
quem nẩo se resignou de todo, mas nunca deixou de amar a vida:

"Ai, ai, ai dêste último homem, está morrendo e ainda sonha com a vida."

"Nem êle a odiou tanto, senão porque a amava muito".

Impossivel, portanto, procurarmos uma única atitude em Machado face à problemática do tempo.

O que há de constante é inquietação permanente do autor agindo sôbre a consciência e ação das personagens e manifestando-se através da elaboração técnica dos contos.

O primeiro aspecto a considerar é o agravamento do problema, que surge já nas primeiras obras Contos Fluminenses (1870) e Histórias da Meia Noite (1873) encarado, porém, dentro do convencionalismo romântico. Tais deficiências, como sabemos, ligam-se às concessões de superficialidade que traduzem a sua mania de futuro, no sentido de elevação social e rompimento com o passado. Foi preciso que o "desencanto pelos homens "o dominasse para que surgisse um novo Machado implacável e penetrante, e o contista se realizasse plenamente, desenvolvendo até as últimas seqüências atitudes e recursos iniciados nos primeiros livros.

Com Papéis Avulsos (1882), liberto dos preconceitos literários e sociais inicia-se uma nova fase em sua obra, onde a experiência do tempo é marcada pela busca angustiante do sentido da vida.

Como seria por demais vasto e pretencioso um exame de todos os aspectos da temática do tempo no conto machadiano, reduziremos nosso estudo às atitudes mais significativas do autor diante do fluir e da irreversibilidade do mesmo e da sua teoria cíclica.

\section{FLUIR LÓGICO E ILOGICO DO TEMPO}

O movimento do tempo que flui preocupa Machado, sobretudo, pela sensação de descontinuidade, pelo sentimento de metamorfose que o ser experimenta continuamente, quando transportado pelas águas do tempo.

A Lei da Modificação é o primeiro aspecto a ser considerado, balançando os homens entre a grandeza e a mediocridade.

Medíocres são aquelas personagens em que o tempo atua como agente anestésico e que vão navegando carregadas pelas águas, sem a dignidade de se saberem vítimas.

O tempo, então, é o mago que conduz e acomoda os sonhos, as ambições, os amôres e até os escrúpulos.

$\mathrm{E}^{\prime}$ o que acontece a Caetaninho, personagem de "Fôlha Rôta" ", esquecido das promessas de amor à Luiza e que acaba "casando e engordando", ou com o sofrimento de Félix que padeceu muito com a notícia da separação de Lalau, mas "não há 
nada de eterno neste mundo, e êle próprio acabou casando com Sinhazinha" 6 .

Irônicamente para êstes tudo se resume na filosofia de um par de botas:

"Não há bem que sempre dure, nem mal que se não acabe" ?.

Ou como diz o personagem de "Eterno" s:

"Que é eterno.... Coisas do tempo, dá-se-lhe um punhado de lôdo, êle restitui em diamantes, quando menos em cascalho."

O tempo não só irá acalmar as grandes paixões como também os grandes sonhos:

"Os anos, com seu grande pêso no espírito de Romualdo, cerceavam a compreensão das ambições enormes; e o espetáculo das lutas locais acanhou-lhe o horizonte" 9 .

Até remorsos e escrúpulos são esquecidos graças ao trabaIho do "insigne alquimista", o enfermeiro esquece seu crime graças ao tempo e a fortuna herdada, o amigo esquece a traição.

Porém, a mesma lei da modificação é encarada, muitas vêzes, por um ôngulo idealista: aprimora-se a beleza das mulheres, "que com o tempo vai ficando mais acentuada", as qualidades vão se desenvolvendo.

Suo maior qualidade é a de permitir encontros, pois, e separaçōes não são mais do que "datas trocadas":

"Enquanto quisermos combinar as datas contrárias, perdemos o tempo, mas o tempo andou e combinou tudo" 10 .

"Mas aquilo que o espírito do homem não vence, há de vencê-los o tempo, a quem cabe final razão" "1.

Aquelas personagens, cuja pureza impede aceitor a "razão do tempo", têm a sua solidão marcado pelo gôsto do engano $e$ da frustação.

Assim, a Luiza do Caetaninho morre solteira aos 30 anos, Lalau acata a idéio da tia, Beatriz e Eduardo que esperaram fiéis os dezoito anos de separação arrependem-se de não terem aceitado outras alianças.

Mesmo assim, o homem não abandona sua ânsia de eternidade e procura ogarrar-se a alguma coisa.

$E$ é nêste sentido que a paisagem harmonizava-se com a criatura, como observou Lúcia Miguel Pereira ${ }^{12}$, porque ambos são filhos da Natureza, "mãe e inimiga", manifestaçōes aparentes do mesmo princípio eterno:

"Ao passar pela Glória, Camilo olhou paro o mar, estendeu os olhos pora fora até onde a água e o céu dão um abraço no infinito, e teve assim uma sensação de futuro interminável." ${ }^{13}$

"A beleza física é irmã da paisagem. D. Camilla saboreava nesta fraternidade intima, secreta um sentimento de identidade, uma recordação da vida anterior no mesmo útero divino." 14 
Se o prazer desta identidade está na beleza física, comprende-se o pavor das personagens femininas machadianas ante a idéia de envelhecer.

A mesma D. Camila amou tanto a mocidade e a beleza que tentou parar as águas do tempo numa "reprêsa particular".

Desde os primeiros contos êste é um leitmotiv da psicologia feminina, capaz de tornar as mulheres egoístas e implacáveis.

Em o "Segrêdo de Augusta", 15 a constatação da velhice pela presença dos netos torna a mãe tão egoísta a ponto de impedir o casamento da filha.

A personagem de "A Senhora do Galvão", 16 aceita a idéia do marido ter uma amante, mas não pode perdoar a superação de sua beleza pela outra.

Ser bela é para a mulher a maneira de ser eterna e igualar-se aos imortais.

Peregrino Júnior ${ }^{17}$ acrescenta, a esta identificação com a Natureza, o grave sentimento "do já visto" de regressão à terra - a sedução nitzcheana do "eterno retôrno", a marca da morte.

O relógio funciona como instrumento materializador desta angústia da morte, seu tic-tac é a música do nada, e sua presença se faz sentir nos momentos de solidão, em que o homem enfrenta o pêso do tempo.

Vários são os contos que têm os momentos de maior tensão psicológica marcados pelo ritmo dos relógios.

Jacobina, a personagem de "O Espelho" 18, ao achar-se abandonado por todos, começa a "sentir uma sensação como de pessoa que houvesse perdido tôda ação nervosa". Seu equilibrio é totalmente rompido pela ausência dos outros:

"Minha solidão tomou proporções enormes. Nunca os dias foram mais compridos, nunca o sol abrasou a terra com uma obstinação mais cansativa. As horas batiam de século em século, no velho relógio da sala, cuja pêndula, tic-tac, tic-tac, feria-me a alma interior, como um piparote contínuo da eternidade. .

Não eram golpes da pêndula, era um diálogo do abismo, um cochicho do nada."

A mesma idéia de "horas longas ou curtas", subverte a prisão do tempo cronológico, a presença do relógio é a sua negação, pois como já foi dito: "o relógio não pode marcar o tempo que corre na alegria e se arrasta no sofrimento." 10

O tumulto de sensações dos últimos momentos do suicida escapa a qualquer marcação:

"Ninguém imagina como o tempo corre nas circunstâncias em que estou, os minutos voam como se fôssem impérios e o que é importante nesta ocasião, as fôlhas de papel vão com êles." 20

O oposto ocorre com Bonifácio, que como a personagem de "O Espelho", quase enlouquece ao passar alguns dias totalmente só: 
"As horas eram cada vez mais intermináveis. Nem havio horas, o tempo ia sem as divisões que the dá o relógio, como um livro sem capítulos" $: 1$.

Na medida em que o sentimento do fluir do tempo é experimentado como realidade subjetiva, transmando-se em duração, ganha a obro de Machado o conto, em particular, novas dimensōes.

\section{O TEMPO COMO DURAÇÃO}

Como o narrador de "Viagem à Roda de Mim Mesmo" 2:, Machado encostou-se "à janela da vido, com os olhos no rio que corria embaixo, o rio do tempo, não só para contemplar o curso perene das águas como à espera de ver apontar do lado de cima ou de baixo a galera de ouro e sândalo e velas de sêda, que devia levá-lo a certa ilha encantada".22

Esta "galera" êle encontrou, evidentemente, na transcendência do tempo subjetivo, desenvolvendo o conceito de que há algo de precioso no tempo, conforme a intensidade em que êle é vivido.

"Três meses, três minutos! Eis tôda verdade da vida. Se os puserem sôbre uma grelha, como São Lourenço, cinco minutos erom cinco meses. E ainda se folo em tempo! Há lá tempo! O tempo está em nossas impressões. Há meses para os infelizes e minutos para os venturosos" ":?, já observava uma personagem dos Contos Fluminenses.

A concepção de tempo atemporal vai invadindo a substância e o fato literário e passa a ser revalorizado na consciência das personagens, a trama vai deixando de interessar, concentram-se os efeitos, a tensão poética dá lugar às narrativas derramadas da primeira fase.

O importante, a partir de então, é selecionar da realidade o que serve para retratar uma impressão, a plasticidade do momento, o little moment, o fração dramática mais decisiva:

"E, para começar emendemos Sêneca. Cada dia ao parecer daquele moralista, é, em si mesmo uma vida singular; em outros têrmos, umo vida dentro da vido. Não digo que não; mas porque nāo a acrescentou êle, que muitas vêzes uma só hora é a representação da vida inteira." 24

Porisso, a intensidade com que o narrador de a "Missa do Galo" ":i viveu aqueles curtos minutos em companhia de Dona Conceição, impregnou-se em sua alma como uma atmosfera densa de volúpia e mistério.

O fascínio provocado pelos braços da mulher do escrivão Meneses desencadeia no adolescente as mais controvertida crises de sensibilidade, e mais tarde quando tenta compreender a noção de seus primeiros amôres, tudo porece vago e confuso porque realmente nada de concreto se passou. 
Outra variação sốbre o mesmo tema, encontraremos no conto "Uns Braços" 20, onde o escritor analisa com incomparável orgúcia os movimentos irregulares da doce paixão de Inácio pelos braços de Dona Severina:

"E através dos anos, por meio de outros amôres, mais efetivos e longos, nenhuma sensaçõo achou igual à daquele domingo, na Rua da Lapa, quando êle tinha quinze anos. Êle mesmo exclamava às vêzes, sem saber que se enganava:

- E foi um sonho! um simples sonho!" 20

Os breves momentos de erupção sensual, caracterizados pelo ardor abafado da atmosfera, revela-nos a sensualidade machadiana, tão bem estudada por Augusto Meyer ${ }^{27}$.

Os mesmos contos estabelecem o eixo fundamental em tôrno do qual giram os melhores contos da segunda fase: o passado. $E^{\prime}$ nele que o autor mergulha substituindo a antiga preocupação pelo futuro.

O contista procura então surpreender o momento que passou, a tonalidade musical que a situação nela desperta.

Falamos em tonalidade musical, pois a fina sensibilidade do contista sempre deixa entrever seu amor pela música que poderia ser considerada a concretização do tempo atemporal. No Memorial de Aires ${ }^{28}$, o narrador insiste no amor pela música "que tinha a vantagem de não ser presente, passado, futuro, mas uma cousa fora do tempo".

Vários são os contos em que a ânsia de eterno confunde-se com a música: "A Cantiga do Esponsais" 29, "Um Homem Célebre" 30 "Trio em Lá Menor" 31.

Se a música é um dos aspectos da eternidade o poder de restaurar o passado é o que nos faz senhores da terra.

A busca de sentido da vida no tempo que passou aproxima em vários aspectos Machado de Proust.

Como o romancista francês, Machado compreendeu que o único processo psicológico que poderia levar à recuperação do "tempo perdido" seria a sensação e nunca o raciocínio.

A teoria do memória involuntária é o tema do conto "Papéis Velhos" ${ }^{32}$, analisada através do conflito do deputado Brotero, que chega em casa ardendo de despeito por haver sido preterido na formação do novo ministério. Num desabafo incontido, resolve escrever uma carta rompendo com o conselho, mas a agitação continua e o sono torna-se impossível. Começa, então, a ler umas velhas cartas encardidas pelo tempo. O passado vai ressurgindo em sua mente, os episódios se recompõem:

"De memória em memória, reconstruiu as ilusões de outro tempo, comparou-as com as sensações de hoje, e achou-se roubado. Voluptuoso até a dor, mirou, afincadamente, essas ilusões perdidas, como uma velha contempla as suas fotografias de mocidade." 
Depois de recompor mentalmente os episódios queria agora recompô-los cordialmente reavendo as sensações perdidas. Eis, então, a teorio de Machado:

"Imaginai um soldado a quem uma bala levasse o nariz, e que, acabado a batalha, fôsse procurar no campo o desgraçado apêndice. Suponhomos que o acha entre um grupo de braços e pernas; pega dêle, levanta-o entre os dedos, mira-o, examina-o, é o seu próprio... Mas um nariz? Se o dono lhe puser diante os mais finos perfumes da Arábia, receberá em si mesmo a sensação de aroma? Não, êsse cadóver de nariz nunca mais lhe transmitirá cheiro bom ou mal; pode levá-lo para casa, preservá-lo, embalsamá-lo, é o mesmo. A própria ação de assoar o nariz, embora êle a veja e compreenda, nos outros, nunca mais há de compreender em si, não chegará a reconhecer que efeito The cousava o contacto da ponta do nariz com o lenço. Racionalmente, sabe o que é; sensorialmente, não saberá mais nada."

0 mesmo acontece com a personagem do conto "D. Paula $^{\prime \prime 33}$ que ao contacto das sensações ingênuamente narradas pela sobrinha, encontra algo do outro tempo. Porém, quando tenta emparelhar o coração com o cérebro sente que aquêle reflexo, de há pouco, havia cessado. Em vão repete as palavras da sobrinha, só na cabeça encontra algum vestígio de coisas truncadas.

Mas, se por alguns instantes o tempo foi reversível para D. Paula ou ainda para a personagem do conto "Mariana" 34, a regra fundamental é a da irreversibilidade das sensaçōes que também são atingidas pela lei da modificaçāo.

O fluir do tempo metamorfoseia as criaturas, tornando-as incapazes de recompor os anos perdidos. Como os críticos já observaram, enquanto Proust idealizou sua obra acreditando na repetição fortuita das sensaçōes, Machado conströi seus melhores romances e contos, dentro da visão amarga de uma identificação impossivel.

No já citado conto "O Espelho", o processo de evocação do passado da personagem, como diz o próprio título, é feito através de imagens, pois as sensações não mais coincidiam.

Foi vã a angústia de mestre Romão que passou tôda sua vida à procura de uma nota musical que fixasse a sensação de uma felicidade extinta:

"Voltava ao princípio, repetia as notos, buscava reaver um retalho de sensação extinta, lembrava-se da mulher dos primeiros tempos ..." 35

E' preciso aprender a lição de que são boldados quaisquer esforços, pois nunca somos a mesma pessoa e nunca nos identificamos:

"Não se refazem os homens, e, nesta palavra, estāo compreendidas as mulheres, nem êles nem elas se devolvem oo que foram." 36 
E' com um sorriso amargo que Machado observa o eterno repetir das dôres e alegrias, concluindo que não há nada de novo sôbre o sol.

Na sua tentativa de interpretação da essência humana, esta repetição é valorizado pela mitização.

Hans Meyerhoff ${ }^{37}$, ao estudar a mitologia na literatura moderna (Joyce, Camum, Cocteau), vê nesta redescoberta a identificação da humanidade de forma genérica e atemporal. Define os mitos como "timeless prototypes of human exitence".

No conto machadiano a repetição cíclica da experiência humana é vista, muitas vêzes, através de mitos que identificam a humanidade em geral.

O mito de Ahasverus é retomado não só no conto "Viver" como em "O Imortal" 3s. O judeu errante, como já dissemos, é o mito do homem lúcido, céptico, enfim, da própria situação dilacerada em que se colocou Machado.

Dentro desta concepção de atemporalidade, o eterno feminino é tratado nas proporções de um mito: a eterna Eva.

A mulher como símbolo da vida, fonte de fecundidade e beleza identifica-se com a experiência dos imortais.

No entanto, as mulheres de Machado são Pandoras "mães e inimigas", frias às solicitações do amor, estéreis ou, quando mães, negação da maternidade.

Sendo a problemática do tempo uma noção absorvente, o tema caminhou como procuramos demonstrar, pelas mais variadas direções e perspectivas, desafiando as interpretações, comprovando que ainda há muita coisa para se descobrir em Machado de Assis.

\section{OBRAS CITADAS}

1 - Cardoso, Wilton - Tempo e Memório em Machado de Assis, Belo Horizonte, 1958.

2 - Mochado de Assis - "Lágrimas de Xerxes" in Páginas Recolhidas Obra Completa, vol. II, Liv. J. Aguillar, Rio, 1959.

3 - Machado de Assis - "Viver" in Várias Histórias - Obra cit..

4 - Maya, Alcides - Machado de Assis (Algumas notas sôbre o humour) - Liv. Ed. Jacintho Silva, Rio, 1912.

5 - Machado de Assis - "Fôlha Rôta" in Outros Contos - Obra cit..

6 - Machado de Assis - "Casa Velha" in Outros Contos - Obra cit..

7 - Machado de Assis - "Filosofia de Um Par de Botas" in Páginas Recolhidos - W. M. Jackson, Rio, 1938.

8 - Machado de Assis - "Eterno" in Páginas Recolhidas - Obra cit..

9 - Machodo de Assis - "O Programa" in Outros Contos - Obra cit..

10 - Machado de Assis - "Datas Trocadas" in Outros Contos - Obro cit..

11 - Mochado de Assis - "Miss Dolar" in Contis Flumisenses - Obro cit..

12 - Miguel-Pereiro, Lúcio — "Machado de Assis" - Liv. Ed. J. Olympio, Rio, 1955. 
13 - Machado de Assis - "A Cartomante" in Várias Histórias - Öbra cit..

14 - Machado de Assis - "Uma Senhora" in Histórias Sem Data - Obra cit..

15 - Mochado de Assis - "O Segrêdo de Augusta" in Contos Fluminenses Obra cit..

16 - Machado de Assis - "A Senhora do Galvāo" in Histórias Sem Data Obro cit..

17 - Peregrino Júnior - Doença e Constituição de Machado de Assis Liv. J. Olympio, Rio, 1938.

18 - Machodo de Assis - "O Espelho" in Papéis Avulsos - Obro cit..

19 - Côrtes Riedel, Dirce - O Tempo no Romance Machadiono - Liv. São José, Rio, 1959.

20 - Mochodo de Assis - "Último Capitulo" in Histórios Sem Data - Obra cit..

21 - Mochado de Assis - "Só" in Outros Contos - Obra cit..

22 - Machodo de Assis - "Viagem a Roda de Mim Mesmo" in Outros contos - Obro cit..

23 - Machado de Assis - "Viagem à Rodo de Mim Mesmo" in Outros Contos - Obra cit..

24 - Machado de Assis - "Linha Reta Linha Curva" in Contos Fluminenses

25 - Machado de Assis - "Missa do Galo" in Páginas Recolhidas - Obra cit..

26 - Machado de Assis - "Uns Braços" in Várias Histórios - Obra cit..

27 - Meyer, Augusto - "Da Sensualidode" in Machado de Assis (1955-1958). Liv. São José, Rio, 1958.

28 - Mochodo de Assis - Memorial de Aires - Obra Completa, vol. I, Liv. j. Aguillar, Rio, 1959.

29 - Machado de Assis - "Contiga de Esponsais" in Histórias Sem Data - Obra cit..

30 - Machado de Assis - "Um Homem Célebre" in Várias istórias - Obra cit..

31 - Machado de Assis _ "Trio em Lá Menor" in Várias Histórias - Obro cit..

32 - Machado de Assis _- "Papéis Velhos" in Páginas Recolhidas - Obra cit..

33 - Machado de Assis - "D. Poulo" in Várias Histórias - Obro cit.

34 - Machado de Assis - "Mariana" in "Várias Histórias - Obro cit.

35 - Machado de Assis - "Cantiga de Esponsais" - Obra cit.

36 - Machodo de Assis - "Entre Duas Datas" in Outros Contos - Obra cit.

37 - Meyerhoff, Hans - Time in Literature - University of California Press

- Beskeley and Los Angeles, 1955.

38 - Machado de Assis — "O Imartal" in Outros Contos - Obra cit.. 